\title{
Monitoring Cooling Agents Applied to the Skin of Normal Subjects by Quantitative Thermal Imaging
}

by E. F.J. Ring, R. Vardasca, U. Bajwa

\begin{abstract}
Medical Imaging Research Unit, Faculty of Advanced Technology, University of Glamorgan Pontypridd CF 37
\end{abstract} $1 D L$ Wales, United Kingdom

\begin{abstract}
Topical application of cold applied to the skin can be beneficial particularly after minor trauma such as those resulting from sport. This study evaluates a new product that is designed to deliver a sustained cooling effect to the skin. Volunteer subjects were tested with the Deep Freeze Cold Patch applied to the arm on one day and to the thigh on another occasion. The untreated limb was used as a control. Infrared thermography was used under controlled conditions to image the skin at regular time intervals up to three hours, by briefly peeling the patch away from the skin, followed by rapid replacement to the same area of skin. Significant cooling of the area of skin treated with Deep freeze Cold Patch was objectively shown.
\end{abstract}

\section{Introduction}

Deep Freeze Cold Patch (Mentholatum Co Ltd, UK) is a product designed to produce a cooling effect when applied to the skin. This study has objectively investigated the extent of cooling and the effect of time of application of the Deep Freeze Cold Patch to the skin of healthy volunteers. Earlier studies with the aerosol, and the gel formulations of Deep Freeze (Mentholatum Co Ltd, UK) has shown that these treatments are more acceptable than ice packs applied to the skin, the cooling effects being more gentle and also more sustained.1,2

The aim of this study was to investigate the cooling effect of the new product designed to provide a sustained topical cooling effect when applied to the skin. This study reports the thermal effects from the application of the product Deep Freeze Cold Patch to the forearm and the anterior thigh of human healthy volunteers using infra red thermal imaging.

\section{Study design}

Twelve normal healthy volunteers were recruited to the study. After acclimatisation in a temperature controlled laboratory $\left(23^{\circ} \mathrm{C} \pm 1^{\circ} \mathrm{C}\right)$ for 15 minutes, with both arms and legs exposed. One limb was cooled with the patch and the other left exposed to the ambient to act as a control. The patch measuring $10 \times 15 \mathrm{~cm}$ was applied to the mid anterior forearm on the first test, and to the mid anterior thigh on the second test. The tests on each subject were conducted on different days to avoid any persistent effects from skin cooling that might influence the response. The time duration for application of the patch (tested by a pilot study) was maintained in position for three hours at each site.

\section{Experimental conditions}

All subjects were acclimatised with bare arms and legs in the draught free temperature controlled room at $23^{\circ} \mathrm{C}\left( \pm 1^{\circ} \mathrm{C}\right)$ for 15 minutes, or until a stable thermal image was obtained. Non contact thermal imaging was performed with an A40 FLIR digital infrared camera calibrated at $30^{\circ} \mathrm{C}$ for quantitative temperature measurements. The subject was positioned with both arms placed forwards on a flat surface. The IR focal plane array camera was positioned at $90^{\circ}$ from the dorsal surface of the arms and hands. Automatic sequence grabbing of the images was achieved with the special infrared imaging software CTHERM.

The process was repeated on a separate day for application to the legs. For this test the subject was seated on a chair, with the camera set vertically above to image both legs simultaneously, both feet on the floor. The patch was applied to one mid thigh, the choice of left or right for the patch application was randomised.

During the study, temperature sampling of the area of skin covered by the patch was performed by peeling the patch back (approximately 95\%) for infrared imaging measurements and then carefully replaced on exactly the same area of skin.

\section{Volunteers \& Method}

12 volunteers were recruited between the ages of 18 and 55 years, 10 males and two females were tested under identical conditions. The ages ranged from 19-30 yrs, the mean of 10 males was 23 yrs, and two females 19 , and $21 \mathrm{yrs}$ were included. The mean age of the whole group was 22.5 years. Each volunteer attended on two occasions, with each visit lasting for three hours 30 minutes including acclimatisation to achieve a stable baseline temperature. The test laboratory was air-conditioned at $23^{\circ} \mathrm{C} \pm 1.0^{\circ} \mathrm{C}$. No direct draughts on the subject were allowed throughout the study. 
Basic demographic data, including name, age, and gender were recorded. In the reported data, personal identification has been replaced by an index code to preserve confidentiality. A questionnaire was used to assess the subjective effects of the patch application by each volunteer during and after the test.

A FLIR A40 thermal camera digitally linked to an image processing station was mounted vertically over the seated subjects, who had either their arms resting on a table, or their thighs positioned from the sitting position, parallel to the floor. Accurate focusing was ensured prior to each captured image.

To perform the infrared image during the application period of the patch, the dressing was peeled back from the skin to $5 \mathrm{~mm}$, to expose the treated area. Immediately after the image was recorded, the patch was replaced in the same position. The time delay for this process was less than 10 seconds. The pilot test showed that this was the most effective method to use. See page 3

Infrared thermal images (thermograms) were recorded as follows:

Baseline before application, then at the following time intervals - 15,30, 45, 60, 90, 120, 150, and 180mins.

RESULTS

Temperature data extracted from the thermal images of all subject volunteers, mean of 12 subjects are summarised in table 1 (arm) and table 2 (thigh) application sites.

The data are plotted in figures 1 and 3 . The thermograms from one subject are shown in figure 2

\begin{tabular}{|l|l|l|l|l|l|l|}
\hline \multirow{2}{*}{} & \multicolumn{4}{|c|}{ ROI Mean temperatures from the arm Average $(\mathrm{N}=12)$} \\
\cline { 2 - 7 } & \multicolumn{3}{|c|}{ Cold Patch } & \multicolumn{3}{c|}{ Control } \\
\cline { 2 - 7 } & Min $\left({ }^{\circ} \mathrm{C}\right)$ & Mean $\left({ }^{\circ} \mathrm{C}\right)$ & $\mathrm{SD}\left({ }^{\circ} \mathrm{C}\right)$ & $\min \left({ }^{\circ} \mathrm{C}\right)$ & Mean $\left({ }^{\circ} \mathrm{C}\right)$ & $\mathrm{SD}\left({ }^{\circ} \mathrm{C}\right)$ \\
\hline baseline & 30.02 & 32.37 & 0.49 & 27.39 & 32.36 & 0.6 \\
\hline $15 \mathrm{~min}$ & 28.17 & 29.54 & 0.49 & 27.67 & 32.57 & 0.65 \\
\hline $30 \mathrm{~min}$ & 27.98 & 29.26 & 0.61 & 27.78 & 32.57 & 0.63 \\
\hline $45 \mathrm{~min}$ & 28.11 & 29.19 & 0.52 & 28.00 & 32.51 & 0.55 \\
\hline $60 \mathrm{~min}$ & 28.09 & 29.45 & 0.58 & 27.35 & 32.35 & 0.59 \\
\hline $90 \mathrm{~min}$ & 29.25 & 30.35 & 0.49 & 28.06 & 32.21 & 0.57 \\
\hline $120 \mathrm{~min}$ & 29.9 & 31.13 & 0.45 & 27.75 & 32.15 & 0.62 \\
\hline $150 \mathrm{~min}$ & 30.25 & 31.51 & 0.36 & 27.91 & 32.17 & 0.57 \\
\hline $180 \mathrm{~min}$ & 30.12 & 31.67 & 0.42 & 27.13 & 32.26 & 0.62 \\
\hline
\end{tabular}

Table 1. Mean temperatures of Deep Freeze Cold Patch applied to one arm (12 subjects). The minimum and mean and standard deviation values are obtained from the fixed region of interest (ROI) used in the image analysis, for the whole cohort of subjects

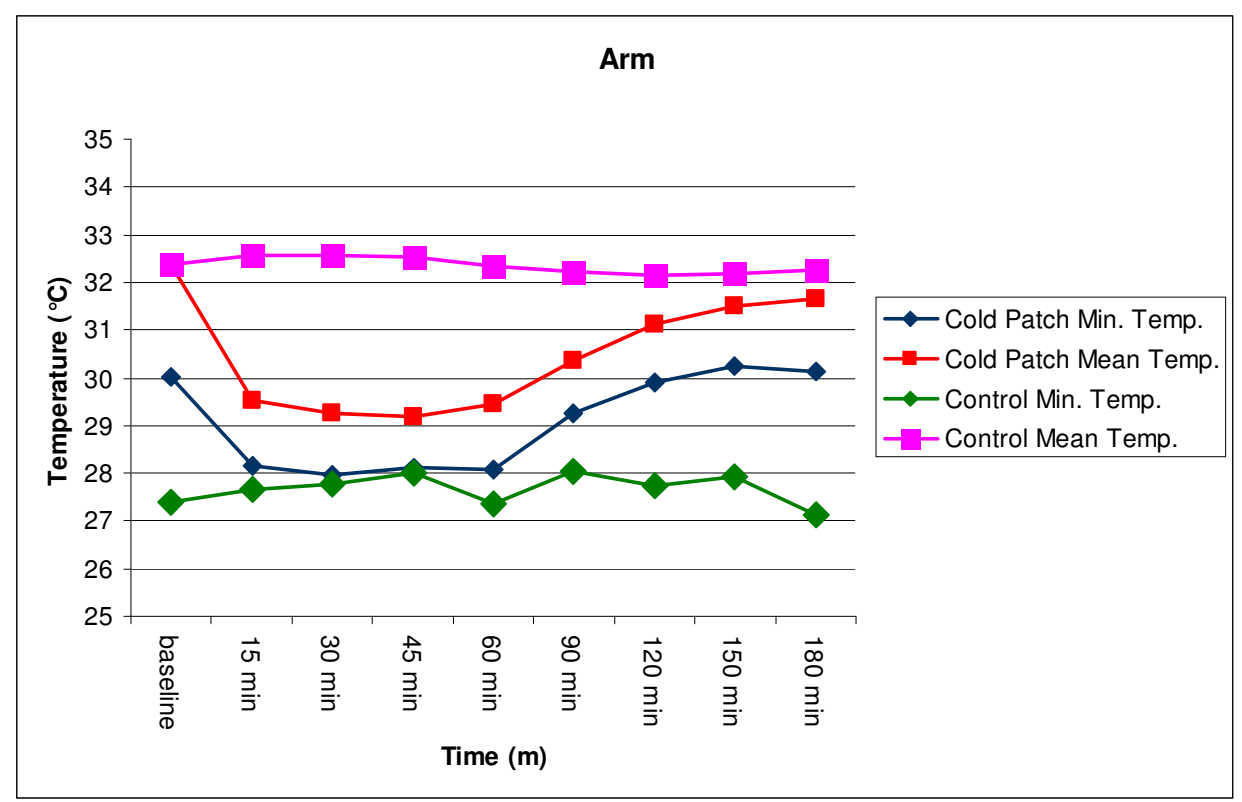

Fig. 1. The mean and minimum temperatures obtained from the standard region of interest over the treated area of skin. The control temperatures are taken from the contra-lateral untreated limb using the same ROI 


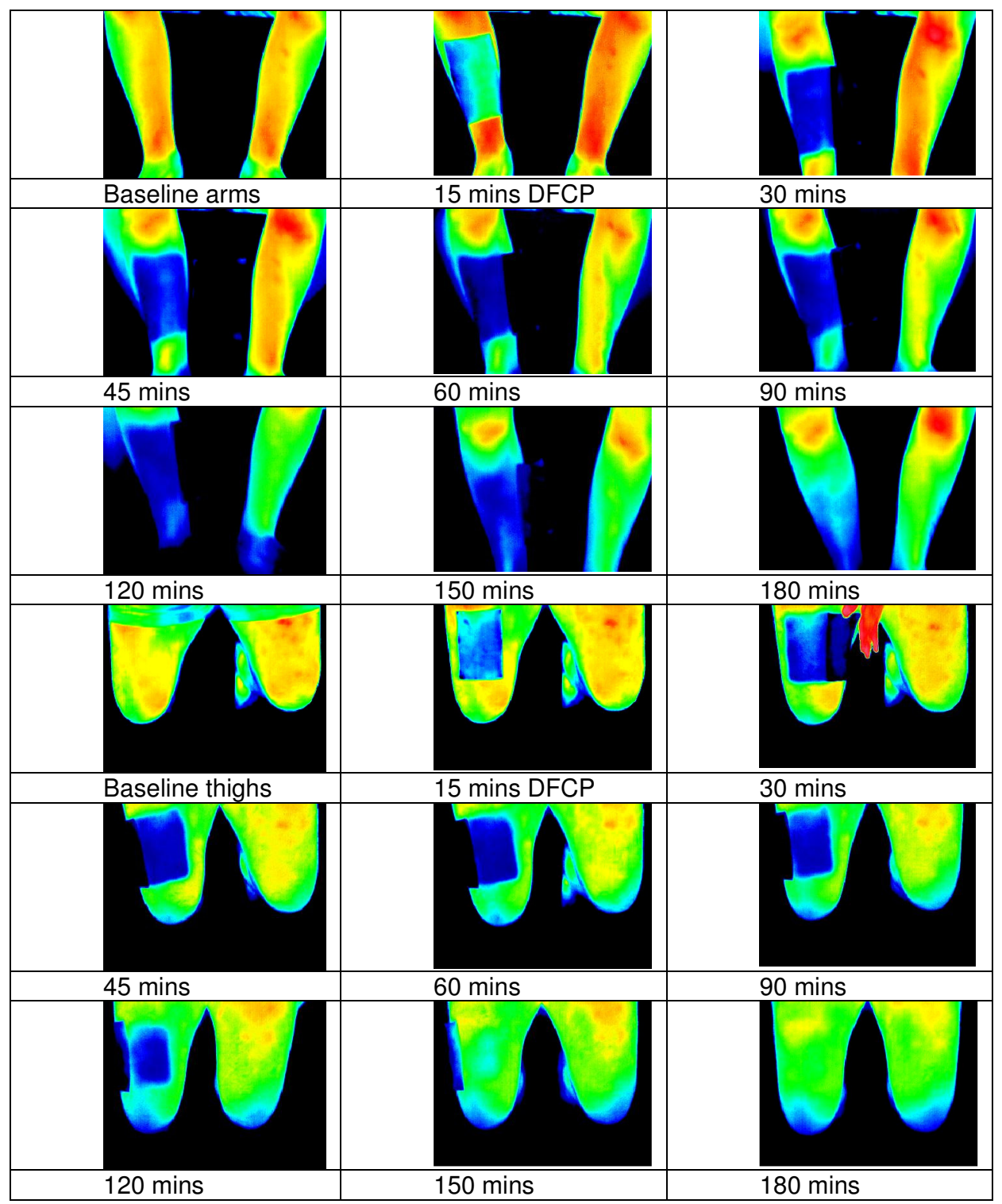

Fig. 2 Infrared thermograms taken throughout the study illustrating the skin cooling effect on the forearm and thigh of one volunteer

\begin{tabular}{|l|c|c|}
\hline \multirow{2}{*}{} & \multicolumn{2}{|c|}{ T Differences (Cold Patch-Control) } \\
\cline { 2 - 3 } & Min $\left({ }^{\circ} \mathrm{C}\right)$ & Mean $\left({ }^{\circ} \mathrm{C}\right)$ \\
\hline baseline & 2.63 & 0.01 \\
\hline $15 \mathrm{~min}$ & 0.5 & -3.03 \\
\hline $30 \mathrm{~min}$ & 0.2 & -3.31 \\
\hline $45 \mathrm{~min}$ & 0.11 & -3.32 \\
\hline $60 \mathrm{~min}$ & 0.74 & -2.9 \\
\hline $90 \mathrm{~min}$ & 1.19 & -1.86 \\
\hline $120 \mathrm{~min}$ & 2.15 & -1.02 \\
\hline $150 \mathrm{~min}$ & 2.34 & -0.66 \\
\hline $180 \mathrm{~min}$ & 2.99 & -0.59 \\
\hline
\end{tabular}

Table 2 The mean temperature differences obtained from all 12 subjects arms i.e. Treated subtracted from control untreated skin areas 


\begin{tabular}{|l|l|l|l|l|l|l|}
\hline \multirow{3}{*}{} & \multicolumn{5}{|c|}{ ROI Mean temperatures from the thigh Average $(\mathrm{N}=12)$} \\
\cline { 2 - 7 } & \multicolumn{3}{|c|}{ Cold Patch } & \multicolumn{3}{c|}{ Control } \\
\cline { 2 - 7 } & Min $\left({ }^{\circ} \mathrm{C}\right)$ & Mean $\left({ }^{\circ} \mathrm{C}\right)$ & $\mathrm{SD}\left({ }^{\circ} \mathrm{C}\right)$ & Min $\left({ }^{\circ} \mathrm{C}\right)$ & Mean $\left({ }^{\circ} \mathrm{C}\right)$ & $\mathrm{SD}\left({ }^{\circ} \mathrm{C}\right)$ \\
\hline baseline & 30.39 & 31.25 & 0.34 & 30.26 & 31.31 & 0.35 \\
\hline $15 \mathrm{~min}$ & 26.66 & 27.66 & 0.39 & 30.15 & 30.98 & 0.29 \\
\hline $30 \mathrm{~min}$ & 27.06 & 27.86 & 0.37 & 30.56 & 31.51 & 0.31 \\
\hline $45 \mathrm{~min}$ & 27.08 & 27.86 & 0.38 & 30.47 & 31.44 & 0.31 \\
\hline $60 \mathrm{~min}$ & 26.77 & 27.62 & 0.44 & 30.19 & 30.98 & 0.31 \\
\hline $90 \mathrm{~min}$ & 27.66 & 28.56 & 0.48 & 30.22 & 31.16 & 0.31 \\
\hline $120 \mathrm{~min}$ & 28.38 & 29.31 & 0.45 & 29.92 & 30.84 & 0.32 \\
\hline $150 \mathrm{~min}$ & 29.36 & 30.19 & 0.37 & 30 & 30.99 & 0.33 \\
\hline $180 \mathrm{~min}$ & 30.05 & 30.81 & 0.3 & 30.03 & 31.1 & 0.36 \\
\hline
\end{tabular}

Table 3 The mean temperatures obtained from 12 subjects with data from the two regions of interest ROI on the treated and control thigh area

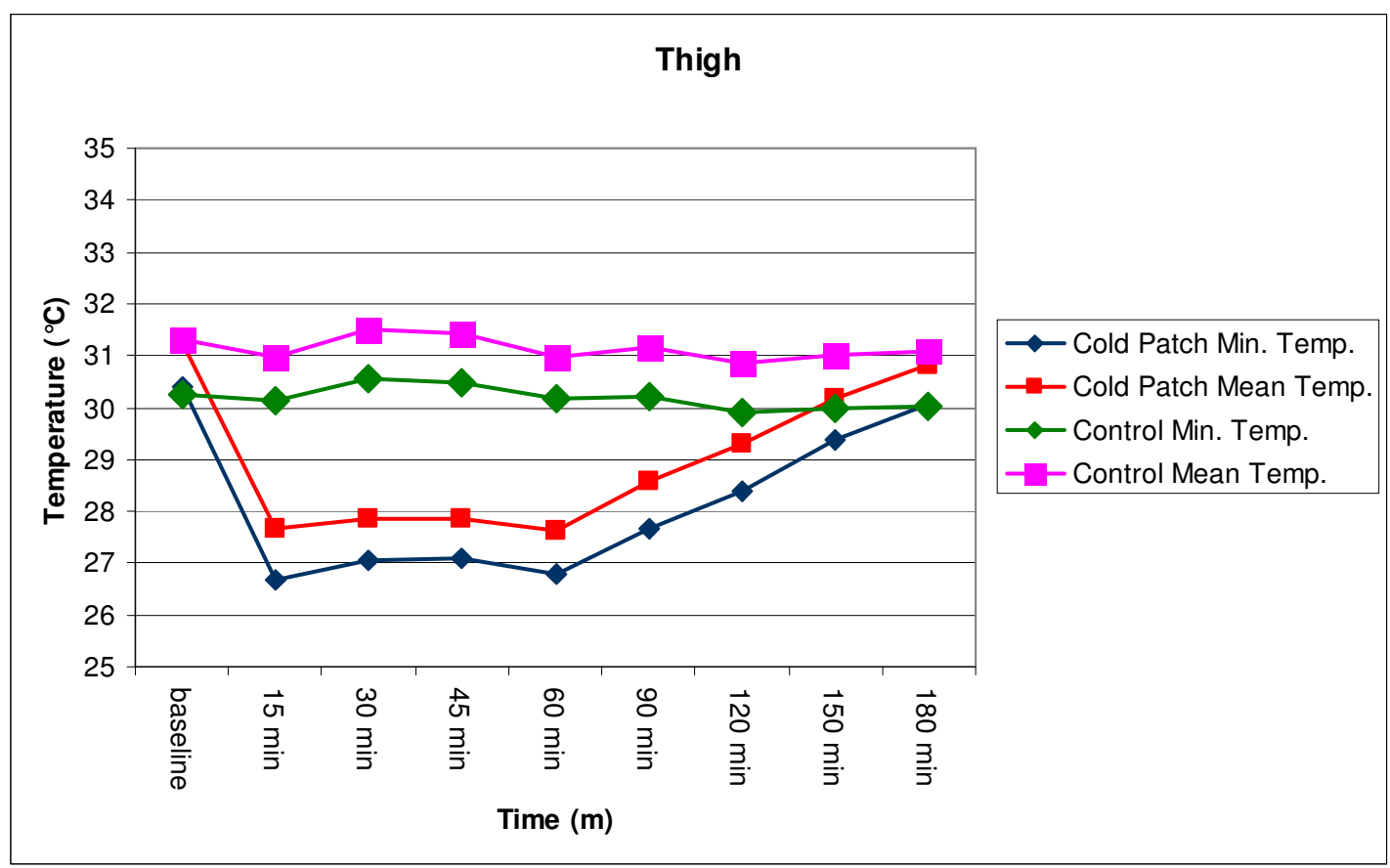

Fig. 3 The mean temperatures and minimum temperatures of 12 subjects obtained from the regions of interest of the thermograms of the treated and control thigh images

\begin{tabular}{|c|l|l|}
\hline \multirow{2}{*}{} & \multicolumn{2}{|c|}{ Differences (Cold Patch-Control) } \\
\cline { 2 - 3 } & Min $\left({ }^{\circ} \mathrm{C}\right)$ & Mean $\left({ }^{\circ} \mathrm{C}\right)$ \\
\hline baseline & 0.13 & -0.06 \\
\hline 5 min & -3.49 & -3.32 \\
\hline $30 \mathrm{~min}$ & -3.5 & -3.65 \\
\hline $45 \mathrm{~min}$ & -3.39 & -3.58 \\
\hline $60 \mathrm{~min}$ & -3.42 & -3.36 \\
\hline $90 \mathrm{~min}$ & -2.56 & -2.6 \\
\hline $120 \mathrm{~min}$ & -1.54 & -1.53 \\
\hline $150 \mathrm{~min}$ & -0.64 & -0.8 \\
\hline $180 \mathrm{~min}$ & 0.02 & -0.29 \\
\hline
\end{tabular}

Table 4 The temperature differences for minimum and mean temperatures from the 12 subjects obtained from the thermograms of the thigh 


\section{STATISTICAL ANALYSIS}

A single paired student $t$ test was applied to the mean temperature differences throughout the period of the study, i.e. 3 hours from application of the Deep Freeze Cold Patch. The statistical significance of temperature change between control and treated sites is shown in Table 5 below, signifying some significant difference from the control side of the body persisting at 3 hours, but rapidly reducing at that stage.

\begin{tabular}{|l|l|l|}
\hline values & $(P \leq t)$ & $(P \leq t)$ \\
\hline Time (mins) & arm & thigh \\
\hline 15 & 0.000000005 & 0.0000000002 \\
\hline 30 & 0.000000002 & 0.0000000001 \\
\hline 45 & 0.0000003 & 0.0000000002 \\
\hline 60 & 0.0000003 & 0.000000002 \\
\hline 90 & 0.00001 & 0.00000002 \\
\hline 120 & 0.0005 & 0.00000007 \\
\hline 150 & 0.003 & 0.000002 \\
\hline 180 & 0.002 & 0.008 \\
\hline
\end{tabular}

Table 5 The student $t$ test results showing significant changes in temperature between the two sites compared to the contra lateral untreated limb

Subjective response to Deep Freeze Cold Patch application

A questionnaire was completed by the volunteers to ascertain their subjective reactions to the application of the Deep Freeze Cold Patch. A total of 14 questions were supplied, the following indicates a sample of the

Results obtained.

Question: How would you describe the sensation from the patch? Or how did the patch feel when first placed on the skin? Answers: Cool 3, Cold 9

Question: Did you feel this was too cold? Not cold enough? About right?

Answers: Too cold: 1, Not cold enough: 0, About right: 11

Question: Overall impression of the patch?

Answers: Very Good: 9, acceptable: 2, Cold:1.

Question: What would you use this cooling patch for? Injury, swelling, arthritis

Answers: Injury: 12, Swelling: 4, Arthritis: 1

The impact impression was $75 \%$ classified as cold with the other 3 subjects $(25 \%$ registered as cool when DFCP was first applied to the arms). The results on the thigh were not identical with 10/12 (83\%) reporting cold rather than cool.

The majority $8 / 9$ replies felt the impact of cold between 5 and 7 minute after application. On the forearm, $11 / 12$ considered the degree of cooling to be about right (92\%), but on the thigh the subjective reply was different. 3 subjects $(25 \%$ ) considered the temperature to be too cold, 1 subject ( $8 \%$ of sample) considered the patch to not be cold enough, while $8(67 \%)$ though the cooling effect was about right.

Overall, the comments were very favourable, all volunteers said they would use Deep freeze Cold patches for injuries, and liked the length of time it remained active in the cooling effect on the skin. All but one subject found the aroma to be pleasant.

\section{Conclusions}

This study has compared the application of a Deep Freeze Cold Patch to the forearm and thigh of 12 healthy volunteers to assess the cooling effects on skin surface temperature. A significant cooling of skin temperature compared to the contra-lateral control limb was observed over the 3 hour test period. Table 1 illustrates that the results were optimal on the arm for the first hour, though still significantly cooler than the control sites for the remaining two hours tested. Most of the volunteers reported that there was a longer lasting subjective cooling of the applied site beyond 3 hours but with lessening magnitude. 
The results on the thigh of the same volunteers tested on a separate occasion from the forearm tests, showed even higher significance, but again reducing at 3 hours.

In the forearm, there are blood vessels present which will have some effect on conducting local cooling away from the site. On the thigh, the dermis is thicker and the muscle mass of the quadriceps greater, which could explain the slightly more efficient cooling by the patch application. This is also shown in Figures 1 and 3 of minimum and mean temperatures, where there is homogeneity of data on the thigh, but less so on the forearm.

\section{REFERENCES}

[1] E.F.Ring, C.Jones, K.Ammer, P.Plassmann, T.Bola Cooling effects of Deep Freeze Cold Gel applied to the skin, with and without rubbing, the lumbar back. Thermology international,14.2 (2004) 64-70

[2] E.F.Ring, C.Jones, K.Ammer, P.Plassmann, T.Bola Cooling effects of Deep Freeze Cold Gel compared to that of an ice pack applied to the skin. Thermology international,14.3 (2004) 93-98. 